\title{
An Abstract: Brand Orientation as Antecedent to Brand Value: Construct Redefinition and Conceptual Model
}

\author{
Priyanka Sharma, Shashi Shekhar Mishra, and Raghu Nandan Sengupta
}

\begin{abstract}
Brand orientation is a critical factor in driving the differential advantage for firms. However, there are gaps in which the construct and its antecedents/outcomes are defined. Content analysis, of various definitions, implies that it should be a multidimensional construct which is guided by several parameters, namely, corporate vision, organizational culture, market dynamics, and stakeholder objectives. Thus, a systematic literature review integrates structure-conduct-performance theory, resource-based theory, and market orientation concepts to redefine brand orientation as a three-dimensional construct with the following interdependent components: cognition, creation, and calibration. Secondly, it suggests that organizational factors (culture and philosophy, interdepartmental coordination, and growth intention) and market factors (competitor intensity, brand sensitivity of stakeholders, and market life cycle) affect the degree of brand orientation. Thirdly, it extends that brand orientation leads to the brand value which comprises of three elements, existential value, experiential value, and economic value, drawn on the theory of existentialism and the meanings associated with consumption. Thus, firms cannot transform themselves into brand-oriented companies until systemic arrangements are made to consider organizational and market factors. A firm should formulate a "brand development plan" by "knowing thyself and environment," "investing into brand identity and image-building programs," and "brand review."
\end{abstract}

P. Sharma $(\varangle) \cdot$ S. S. Mishra $\cdot$ R. N. Sengupta

Indian Institute of Technology, Kanpur, India

e-mail: psharma@iitk.ac.in; ssmishra@iitk.ac.in; raghus@iitk.ac.in 